\title{
"Motion-specific Headache": A Predictor for Diagnosis and Favorable Prognosis after Surgery in Young Patients with Chiari Malformation Type 1
}

\author{
Yoshikuni KOTAKI, ${ }^{1}$ Gohsuke HATTORI, ${ }^{1}$ Hisaaki UCHIKADO, ${ }^{1}$ Satoru KOMAKI, ${ }^{1}$ \\ Nobuyuki TAKESHIGE, ${ }^{1}$ Takahiro MIYAHARA, ${ }^{1}$ Yu HASEGAWA,,${ }^{1,2}$ \\ and Motohiro MORIOKA ${ }^{1}$ \\ ${ }^{1}$ Department of Neurosurgery, Kurume University School of Medicine, Kurume, Fukuoka, \\ Japan \\ ${ }^{2}$ Department of Pharmaceutical Sciences, School of Pharmacy at Fukuoka, International \\ University of Health and Welfare, Fukuoka, Fukuoka, Japan
}

\begin{abstract}
As headache is known as one of the most common symptoms in the patients with Chiari malformation type 1 (CM1), it is difficult to find out CM1-related headache among the symptoms because headache itself is commonly seen. Herein, we retrospectively review the cases of six CM1 patients complaining only of headache by which they complained of deterioration in daily life activities. The symptom of headache worsened during anteflexion $(n=2 ; 33 \%)$, retroflexion $(n=1 ; 17 \%)$, jumping $(n=3 ; 50 \%)$, going up the stairs $(n=1 ; 17 \%)$, and running $(n=1 ; 17 \%)$. Mean age at the onset was 15.7 years old (ranging 11-18) and four out of six were female. These inductive factors were clearly different from "Valsalva-like maneuvers," although the mechanism might originate from dynamic tonsil changes. We named these headaches as "motion-specific." These headaches radiated to the posterior side. MRI revealed that the extent of tonsillar ectopia was $11.3 \mathrm{~mm}$, while syringomyelia was observed in three out of six patients $(50 \%)$. All patients underwent surgical treatment, with the "motion-specific headache" completely disappearing 12.5 days thereafter. Although headaches are common, "motion-specific headache" may be a good candidate symptom to distinguish CM1 patients, especially among teenagers with headaches, and a good predictor for favorable outcomes after surgical treatment.
\end{abstract}

Keywords: Chiari malformation type 1, young adult, surgery, headache

\section{Introduction}

Chiari malformation type I (CM1), the most common type of this malformation, is characterized by a cerebellar tonsillar position $>5 \mathrm{~mm}$ below the foramen magnum. ${ }^{1)} \mathrm{CM} 1$ induces various symptoms related to brain stem compression and syringomyelia, which are observed from the second to third decade of life. ${ }^{2)}$

Headache is a well-known major symptom in CM1 patients and is found in $25-50 \% .^{3-5)}$ The

Received December 23, 2020; Accepted May 31, 2021

Copyright $@ 2021$ The Japan Neurosurgical Society This work is licensed under a Creative Commons AttributionNonCommercial-NoDerivatives International License. radiological prevalence of CM1 in patients with headache is reported as $0.5-1.0 \%$ both in adults and in children. ${ }^{6-8)}$ The International Headache Society classification (third edition) has included CM1-specific headache and issued detailed diagnostic criteria as follows: "Headache caused by CM1, usually occipital or suboccipital, of short duration $(<5 \mathrm{~min})$ and provoked by cough or other Valsalvalike manoeuvres."9) Although headache is a common symptom and CM1 patients often show other types of headaches such as migraine and tension-type headaches, it is important to distinguish between CM1-specific and other types of headaches because of the possible favorable outcomes of surgical treatment. ${ }^{10,11)}$ Although this type of headache is typically induced by the difference of pressure gradients, 
created between the intracranial space and spinal canal by a Valsalva-like maneuver, here we report on six CM1 patients with a unique headache induced by specific movements, which are not Valsalva-like maneuvers. We have termed this headache as "motion-specific headache" and herein provide its characteristics and the surgical treatment followed in these patients.

\section{Methods}

This retrospective clinical study was conducted between July 2013 and June 2019 at Kurume University Hospital. The study protocol was approved by the Ethics Committee of Kurume University Hospital (2020-082). We collected the clinical data of patients diagnosed as CM1 complaining only of headache. The following patients were excluded: patients with other symptoms, including neurologic signs, other malformations of the central nervous system, CM type 2, genetic syndromes, and secondary herniation of cerebellar tonsils. All patients underwent preoperative morphologic assessments using cerebral and spinal MRI. The following criteria were used to diagnose CM1: 1) $\geq 5 \mathrm{~mm}$ caudal descent of the cerebellar tonsils or 2) $\geq 3 \mathrm{~mm}$ caudal descent of the cerebellar tonsils plus $\geq 1$ indicator of crowding of the subarachnoid space in the area of the craniocervical junction. ${ }^{1-9)}$ The selected patients underwent foramen magnum decompression (FMD) through a $2.5 \times 2.5 \mathrm{~cm}$ craniotomy, and then underwent additional surgical procedures such as removal of the posterior C1 arch, duraplasty, removal of the outer dura layer, and tonsil resection. These additional procedures depended on CM1 severity (symptoms' duration, extent of tonsillar ectopia, and tonsil volume).

\section{Results}

From July 2013 to June 2019, 13 CM1 patients were surgically treated in our neurosurgical department and 10 patients suffered from headache related to CM1. Of these 10 patients, 6 patients complained only of headache induced by specific movements. Their characteristics and clinical data are shown in Tables 1 and 2. Mean age at headache onset was 15.7 years old and four out of six were female. The

Table 1 The characteristics in the six CM1 patients with headache

\begin{tabular}{|c|c|c|c|c|c|c|c|c|c|}
\hline Case & Sex & $\begin{array}{c}\text { Age onset/ } \\
\text { operation }\end{array}$ & $\begin{array}{l}\text { Headache } \\
\text { area/ } \\
\text { headache } \\
\text { worsening } \\
\text { movement }\end{array}$ & $\begin{array}{l}\text { Valsalva } \\
\text { headache }\end{array}$ & $\begin{array}{l}\text { Extent } \\
\text { of ton- } \\
\text { sillar } \\
\text { ectopia } \\
\text { (mm) }\end{array}$ & $\begin{array}{l}\text { Syringo- } \\
\text { myelia }\end{array}$ & $\begin{array}{l}\text { Operative } \\
\text { method }\end{array}$ & $\begin{array}{l}\text { Time to dis- } \\
\text { appearance } \\
\text { of headache } \\
\text { after opera- } \\
\text { tion (days) }\end{array}$ & $\begin{array}{l}\text { Postoperative } \\
\text { complication }\end{array}$ \\
\hline 1 & $\mathrm{~F}$ & $\begin{array}{l}13 \text { years/ } \\
13 \text { years }\end{array}$ & $\begin{array}{l}\text { Occipital/ } \\
\text { jumping, } \\
\text { running }\end{array}$ & - & 8 & - & FMD & 4 & - \\
\hline 2 & $\mathrm{~F}$ & $\begin{array}{l}17 \text { years/ } \\
21 \text { years }\end{array}$ & $\begin{array}{l}\text { Occipital, } \\
\text { posterior } \\
\text { neck, } \\
\text { shoulder/ } \\
\text { retroflexion, } \\
\text { jumping }\end{array}$ & - & 8 & - & $\begin{array}{l}\text { FMD + C1 } \\
\text { laminectomy + } \\
\text { tonsillectomy }\end{array}$ & 11 & $\begin{array}{l}\text { Acute } \\
\text { obstructive } \\
\text { hydrocephalus } \\
\text { affected by } \\
\text { a subdural } \\
\text { hygroma }\end{array}$ \\
\hline 3 & $\mathrm{~F}$ & $\begin{array}{l}18 \text { years/ } \\
21 \text { years }\end{array}$ & $\begin{array}{l}\text { Occipital/ } \\
\text { cough, } \\
\text { anteflexion }\end{array}$ & + & 17 & + & $\begin{array}{l}\text { FMD + C1 } \\
\text { laminectomy }\end{array}$ & 24 & - \\
\hline 4 & $\mathrm{M}$ & $\begin{array}{l}17 \text { years/ } \\
17 \text { years }\end{array}$ & $\begin{array}{l}\text { Posterior } \\
\text { neck/ } \\
\text { anteflexion }\end{array}$ & - & 10 & + & $\begin{array}{l}\text { FMD + C1 } \\
\text { laminectomy }\end{array}$ & 27 & $\begin{array}{l}\text { Meningitis due } \\
\text { to CSF leakage }\end{array}$ \\
\hline 5 & $\mathrm{~F}$ & $\begin{array}{l}11 \text { years/ } \\
13 \text { years }\end{array}$ & $\begin{array}{l}\text { Posterior } \\
\text { neck/stepping } \\
\text { the stairs }\end{array}$ & - & 14 & - & $\begin{array}{l}\text { FMD + C1 } \\
\text { laminectomy }\end{array}$ & 5 & - \\
\hline 6 & $\mathrm{M}$ & $\begin{array}{l}18 \text { years/ } \\
18 \text { years }\end{array}$ & $\begin{array}{l}\text { Shoulder/ } \\
\text { jumping }\end{array}$ & - & 11 & + & FMD & 4 & $\begin{array}{l}\text { Transient } \\
\text { mild sensory } \\
\text { disorder in } \\
\text { both upper } \\
\text { limbs }\end{array}$ \\
\hline
\end{tabular}


Table 2 The summarized data in the six CM1 patients with headache

\begin{tabular}{|c|c|}
\hline Characteristics & $\begin{array}{l}\text { Total } \\
\text { six patients }\end{array}$ \\
\hline Mean age at onset (years old) & $15.7(11-18)$ \\
\hline \multicolumn{2}{|l|}{ Sex, n (\%) } \\
\hline Female & $4(67 \%)$ \\
\hline \multicolumn{2}{|l|}{ Main headache area, n (\%) } \\
\hline $\begin{array}{l}\text { Occipital } \\
\text { Posterior neck } \\
\text { Shoulder }\end{array}$ & $\begin{array}{l}3(50 \%) \\
3(50 \%) \\
2(33 \%)\end{array}$ \\
\hline \multicolumn{2}{|l|}{ Headache worsening movement, n (\%) } \\
\hline $\begin{array}{l}\text { Anteflexion } \\
\text { Retroflexion } \\
\text { Jumping } \\
\text { Stepping stairs } \\
\text { Cough } \\
\text { running }\end{array}$ & $\begin{array}{l}2(33 \%) \\
1(17 \%) \\
3(50 \%) \\
1(17 \%) \\
1(17 \%) \\
1(17 \%)\end{array}$ \\
\hline Valsalva headache, n (\%) & $1(17 \%)$ \\
\hline Extent of tonsillar ectopia (mm) & $11.3(8-17)$ \\
\hline Syringomyelia, n (\%) & $3(50 \%)$ \\
\hline Mean age at surgery (years old) & $17.2(13-21)$ \\
\hline \multicolumn{2}{|l|}{ Operative method, n (\%) } \\
\hline FMD & $3(50 \%)$ \\
\hline FMD + C1 laminectomy & $2(33 \%)$ \\
\hline FMD + C1 laminectomy + tonsillectomy & $1(17 \%)$ \\
\hline $\begin{array}{l}\text { Disappearance of CM1-related headache, } \\
\mathrm{n}(\%)\end{array}$ & $6(100 \%)$ \\
\hline $\begin{array}{l}\text { Days from operation to disappearance of } \\
\text { headache (range) }\end{array}$ & $\begin{array}{l}12.5 \text { days } \\
(4-27)\end{array}$ \\
\hline
\end{tabular}

CM1: Chiari malformation type 1, FMD: foramen magnum decompression.

headache radiated to the posterior side, such as the occipital region $(\mathrm{n}=3 ; 50 \%)$, posterior neck $(\mathrm{n}=3$; $50 \%)$, and shoulder $(\mathrm{n}=2 ; 33 \%)$. Various movements including anteflexion $(\mathrm{n}=2 ; 33 \%)$, retroflexion ( $\mathrm{n}=1 ; 17 \%)$, jumping ( $=3 ; 50 \%$ ), going up the stairs ( $\mathrm{n}=1 ; 17 \%)$, coughing $(\mathrm{n}=1 ; 17 \%)$, and running ( $\mathrm{n}=1 ; 17 \%$ ) enhanced their headache, which disappeared within a few minutes. Only one patient had headache induced by the Valsalva maneuver; the others' headaches were not induced by Valsalva-like maneuvers. The patients underwent preoperative MRI, which showed the extent of tonsillar ectopia $(11.3 \mathrm{~mm})$ and syringomyelia $(\mathrm{n}=3$; $50 \%$ ). The mean age at the time of surgery was 17.2 years old, and the patients underwent FMD ( $\mathrm{n}=3 ; 50 \%), \mathrm{FMD}+\mathrm{C} 1$ laminectomy $(\mathrm{n}=2 ; 33 \%)$, or FMD + C1 laminectomy + tonsillectomy $(\mathrm{n}=1$; $17 \%)$. In addition, five underwent duraplasties and one a resection of the outer dura layer. Headache eradication was achieved in all patients. The mean time to headache disappearance after surgery was 12.5 days.

There were three postoperative complications in the CM1 patients. One patient underwent acute obstructive hydrocephalus affected by a subdural hygroma in the dorsal posterior fossa, 31 days after the first surgery, and underwent duraplasty again. The other two patients showed a mild sensory disorder in both upper limbs and meningitis due to cerebrospinal fluid (CSF) leakage, respectively. They were treated conservatively with appropriate drugs, and their complications finally subsided. Finally, half of the patients complained of a weak tension-type headache, but CM1-induced headache has not recurred so far.

\section{Example Case Presentations}

\section{Case 1}

A 13-year-old female was aware of occipital headache during physical exercise. She noticed severe headache when running and jumping, which immediately disappeared after stopping the activity. MRI showed CM1 with an $8 \mathrm{~mm}$ extent tonsillar ectopia (Fig. 1A). She did not complain of headache during neck retroflexion and anteflexion, and no other symptoms were found. The above-mentioned headache was not experienced when coughing or performing other Valsalva-like maneuvers. She underwent FMD and duraplasty, and 4 days after surgery, her headache disappeared. Postoperative MRI revealed successful posterior fossa decompression (Fig. 1B). It was difficult to diagnose CM1 by preoperative CT scan (Fig. 1C), in spite of enhanced CT performed. She was discharged from our hospital with a favorable outcome and the unique headache did not recur even when running or jumping.

\section{Case 2}

A 21-year-old female college student had endured an annoying headache of the occipital region, posterior neck, and shoulder for 4 years. The severity of her headache gradually worsened, and neck retroflexion enhanced the symptoms. When she raised her head to watch a board during a lecture, she frequently noticed an unbearably severe headache, and she could not go to class because of the pain. MRI revealed CM1 with an $8 \mathrm{~mm}$ extent tonsillar ectopia in the neutral position (Fig. 2A). Interestingly, retroflexion worsened the ectopia and enhanced her headache, while anteflexion did not. During postural changes in cases of tonsillar ectopia, the tonsil position becomes $3.5 \mathrm{~mm}$ lower during 

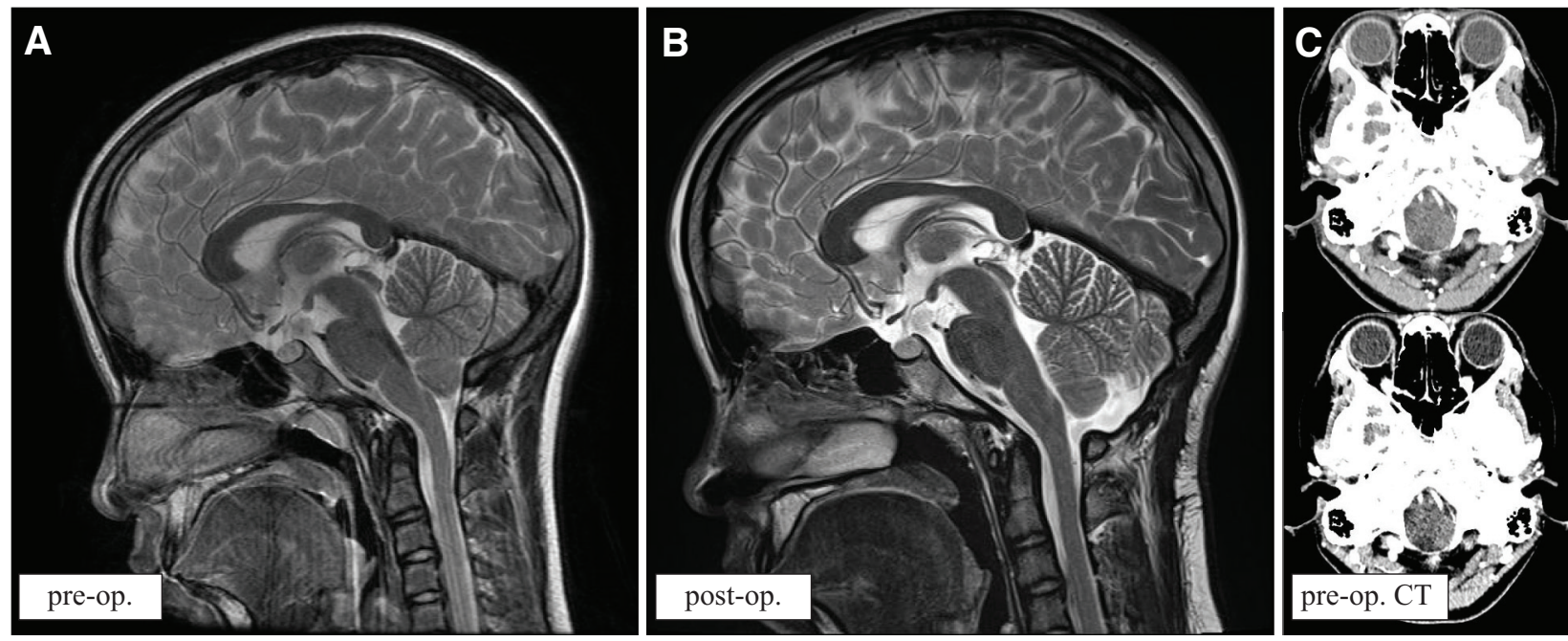

Fig. 1 Thirteen-year-old female. Preoperative MRI sagittal image showing CM1 with an 8 mm tonsillar ectopia extent (preop.; A). After foramen magnum decompression surgery and duraplasty, the CSF space around the foramen magnum widened and tonsil position was upward (postop.; B). Preoperative enhanced CT could not show clearly the findings of CM1 (C). This case is indicated as case 1 in Table 1. CM1: Chiari malformation type 1, CSF: cerebrospinal fluid.

retroflexion than that during anteflexion based on the basion-opisthion line (Fig. 2B and 2C). She underwent FMD, C1 laminectomy, partial tonsillectomy, and duraplasty. Her headache disappeared 11 days after surgery, and postoperative MRI revealed successful posterior fossa decompression (Fig. 2D). It was difficult to diagnose CM1 by preoperative CT scan (Fig. 2E), although the findings suggested CM1 by retrospective observation. She returned to school and did not experience this unique headache during classes.

\section{Discussion}

We have reported on the cases of six young teenagers with a unique headache, "motion-specific headache", which was induced by specific postural changes including neck anteflexion/retroflexion, jumping, going up the stairs, and running. This headache was localized to the occipital region, posterior neck, and shoulder, and disappeared within a few minutes. Furthermore, none of the patients re-experienced the "motion-specific headache" after surgical treatment.

Although the pathophysiology of The International Headache Society classification (third edition)defined CM1-headache remains unclear, several mechanisms have been proposed. Pascual et al. considered that the headache may be attributed to C1 and C2 root compression, owing to further tonsillar herniation by Valsalva-like maneuvers. ${ }^{12)}$ Further, the headache was also suggested to be the result of craniospinal pressure dissociation or due to a sudden increase in intracranial pressure caused by CSF flow obstruction in the subarachnoid space. Although part of the mechanism behind the origin of the headaches in our patients might be similar to Valsalva-like maneuvers, we speculated that the headache could be induced by direct tonsil movement because the headache changed immediately after specific motions. Vertical direct tonsillar movement mainly may compress the dura mater around the foramen magnum, and this direct stimulation of the dura matter may cause specific headache. The fact that five of the six patients with motion-specific headache did not have Valsalva maneuver-induced headache may suggest different headache mechanisms in them. In this study, MRI during postural changes involving retroflexion and anteflexion clearly depicted the tonsillar ectopia change (Fig. 2B and 2C) in the patients with motion-specific headache. We suggest that a combination of the recent novel assessment method using time-spatial labeling, which reveals CSF flow dynamics ${ }^{13)}$ with neck postural change, or other novel methods will clearly show the pathology in future.

Based on our patient characteristics, since all were young the "motion-specific headache" was easily inducible by simple actions performed during their time in school. Then, they tended to be absent from school, and their mental condition became unstable as a result. In addition, as the young people were not likely to explain the detailed symptoms 

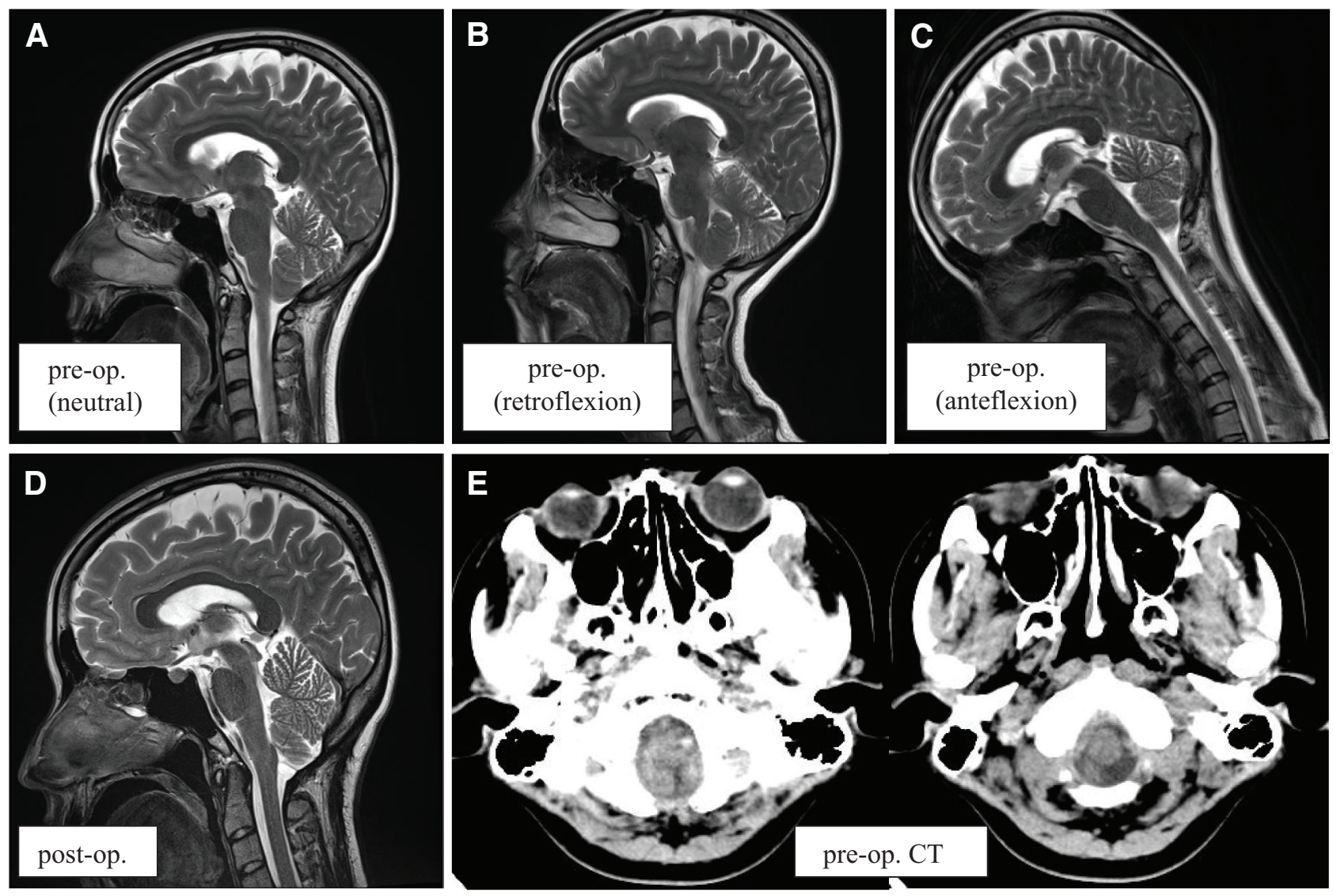

Fig. 2 Twenty-one-year-old female. Preoperative MRI sagittal image showing CM1 with an $8 \mathrm{~mm}$ tonsillar ectopia extent (preop.; A). Regarding the postural change of tonsillar ectopia, tonsil position becomes $3.5 \mathrm{~mm}$ lower at the retroflexion than that at the anteflexion based on basion-opisthion line (B and C). After FMD, C1 laminectomy, partial tonsillectomy, and duraplasty, the CSF space around the foramen magnum widened and tonsil position was upward (postop.; D). It was difficult to diagnose CM1 by preoperative CT scan (E), although the findings suggested CM1 by retrospective observation. This case is indicated as case 2 in Table 1. CM1: Chiari malformation type 1, CSF: cerebrospinal fluid, FMD: foramen magnum decompression.

to family members and doctors, it is quite difficult to approach a more accurate diagnosis. It is very difficult to make a diagnosis of CM1 only by usual CT-scan images (Figs. 1C and 2E) and therefore, it may be misdiagnosed as a mental disorder because of the atypical headache types. We consider it important to ensure that the patients' headaches clearly disappear and that they return to a normal mental state when they discontinue the specific motion, which they anyway cannot continue for a long time. Therefore, we suggest that the "motionspecific headache" could be helpful in diagnosing CM1. We suppose that teenagers tend to present this headache type as atrophy and adhesion are rarely seen in their brains; thus, their tonsils easily move in narrow spaces around the craniovertebral junction with their head motion.

A recent systematic review showed the natural history of asymptomatic and symptomatic CM1, and that the condition of some adult patients with cough headache improved during the follow-up period, while the natural history in the patients with Valsalva-induced headache is undetermined. ${ }^{14)}$ On the other hand, Pepper et al. reported that the postoperative improvement rates of Valsalva-induced headache and non-specific headache were $74 \%$ and $45 \%$, respectively. ${ }^{11)}$ In our patients, "motion-specific headache" completely disappeared after surgery, despite a reduced tension-type headache persisting. Therefore, we believe that the former type of headache can be healed by surgery in CM1 patients.

Five of the six CM1 patients underwent duraplasty in addition to FMD, while one (case five) did not because we performed sufficient decompression by outer dura layer resection. FMD with duraplasty was associated with a lower rate of reoperation $(5.7 \%)$ than bone-only decompression $(53.8 \%)$, and $13 / 14(92 \%)$ CM1 patients with bone-only 
decompression required subsequent duraplasty. ${ }^{4}$ Although outer dura layer resection in addition to bone-only decompression can decrease the risk of CSF leakage-related complications, including subdural effusion and meningitis, we consider that duraplasty could be a standard surgical treatment for patients with CM1 in addition to FMD, especially for patients with motion-specific headache.

\section{Conclusion}

We reported on our experience on six CM1 patients presenting only a unique headache, named "motionspecific headache". This headache was worsened by specific postural changes including anteflexion, retroflexion, jumping, going up the stairs, and running. In addition, the headache radiated toward the occipital region, posterior neck, and shoulder, and disappeared within minutes. Further, surgical treatment could completely eradicate it. "Motionspecific headache" can be a good candidate symptom for CM1 diagnosis, especially among teenagers, and a good predictor for favorable surgical outcomes.

\section{Acknowledgment}

We would like to thank Editage (www.editage.com) for English language editing.

\section{Conflicts of Interest Disclosure}

None.

\section{References}

1) Smith BW, Strahle J, Bapuraj JR, Muraszko KM, Garton HJ, Maher CO: Distribution of cerebellar tonsil position: implications for understanding Chiari malformation. J Neurosurg 119: 812-819, 2013

2) Milhorat TH, Chou MW, Trinidad EM, et al.: Chiari I malformation redefined: clinical and radiographic findings for 364 symptomatic patients. Neurosurgery 44: 1005-1017, 1999

3) Taylor FR, Larkins MV: Headache and Chiari I malformation: clinical presentation, diagnosis, and controversies in management. Curr Pain Headache Rep 6: 331-337, 2002

4) Raza-Knight S, Mankad K, Prabhakar P, Thompson D: Headache outcomes in children undergoing foramen magnum decompression for Chiari I malformation. Arch Dis Child 102: 238-243, 2017

5) Beretta E, Vetrano IG, Curone M, et al.: Chiari malformation-related headache: outcome after surgical treatment. Neurol Sci 38: 95-98, 2017

6) Aitken LA, Lindan CE, Sidney S, et al.: Chiari type I malformation in a pediatric population. Pediatr Neurol 40: 449-454, 2009

7) Bekiesińska-Figatowska M: Magnetic resonance imaging - what important findings can it show in children with headache? Dev Period Med 18: 176-186, 2014

8) Speer MC, Enterline DS, Mehltretter L, et al.: Review article: Chiari type I malformation with or without syringomyelia: prevalence and genetics. $J$ Genet Couns 12: 297-311, 2003

9) Headache Classification Committee of the International Headache Society (IHS) The International Classification of Headache Disorders, 3rd edition. Cephalalgia 38: 1-211, 2018

10) Curone M, Valentini LG, Vetrano I, et al.: Chiari malformation type 1-related headache: the importance of a multidisciplinary study. Neurol Sci 38: 91-93, 2017

11) Pepper J, Elhabal A, Tsermoulas G, Flint G: Symptom outcome after craniovertebral decompression for Chiari type 1 malformation without syringomyelia. Acta Neurochir (Wien) 163: 239-244, 2021

12) Pascual J, Oterino A, Berciano J: Headache in type I Chiari malformation. Neurology 42: 1519-1521, 1992

13) Ohtonari $T$, Nishihara $N$, Ota $S$, Tanaka A: Novel assessment of cerebrospinal fluid dynamics by time-spatial labeling inversion pulse magnetic resonance imaging in patients with Chiari. World Neurosurg 112: e165-e171, 2018

14) Langridge B, Phillips E, Choi D: Chiari malformation type 1: a systematic review of natural history and conservative management. World Neurosurg 104: 213-219, 2017

Corresponding author: Motohiro Morioka, MD, PhD Department of Neurosurgery, Kurume University School of Medicine, 67 Asahimachi, Kurume, Fukuoka 830-0011, Japan.

e-mail:mmorioka@med.kurume-u.ac.jp 